\title{
Hair Lightening of Three Hemodialysis Patients Under Heptaminol
}

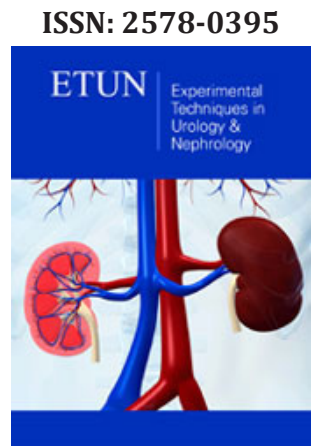

*Corresponding author: Achraf Hendawy, Department of Nephrology, Egypt

Submission: 㭗 March 09, 2019

Published: 觜 March 19, 2019

Volume 2 - Issue 5

How to cite this article: Achraf $\mathrm{H}$, Mona $\mathrm{E}$ S, Hair Lightening of Three Hemodialysis Patients Under Heptaminol. Exp Tech Urol Nephrol. 2(5). ETUN.000549.2019. DOI: 10.31031/ETUN.2019.02.000549

Copyright@ Achraf Hendawy, This article is distributed under the terms of the Creative Commons Attribution 4.0 International License, which permits unrestricted use and redistribution provided that the original author and source are credited.

\author{
Achraf Hendawy* and Mona El Shehemy \\ Department of Nephrology, Egypt
}

\begin{abstract}
Introduction: Dermatologic involvement in hemodialysis patients is characterized by a multitude of different aspects; pruritus, xerosis cutis, hyperpigmentation, actinic elastosis, scalp hair loss and skin infections could occur [1-7]. Alterations in the cutaneous pigmentation is mainly hyperpigmentation on sun-exposed areas and yellowish tinge to the skin. Hypopigmentation is quite rare $[1,6]$. Hair changes are mainly diffuse hair loss of scalp which may be related to telogen effluvium associated with severity of illness, xerosis, pruritus or due to drugs (heparin, anti-hypertensives, lipid-lowering). Sparse body hair, discoloration and dryness of hair, dry and lusterless hair are seen also [1,6,8]. A case of lightening of hair in a dialysis patient under Heptaminol was reported [9]. We report here the same finding with lightening of hair of scalp, eyebrows, eyelashes and total body hair in 3 patients on Hemodialysis and treated by Heptaminol for hypotension.
\end{abstract}

\section{Case Report}

We reported three hemodialysis cases of lightening of scalp hair, body hair as well as eyebrows and eyelashes.

A. The first case is a 23 years old female patient who had been on dialysis for 8 years. She had Systemic Lupus Erythematosus (SLE) and was under steroid, Azathioprine, and Midodrine HCL for hypotension. She developed her symptoms three months after starting Heptaminol for persistent hypotension.

B. The Second case is a 34 years old female on hemodialysis for 7 years due to unknown etiology. She developed the same symptoms 2 months after initiating Heptaminol.

C. The third case is, surprisingly, the husband of the second case, 44 years old on dialysis for 10 years due to obstructive uropathy. He developed the same symptoms 6 months after starting the drug.

Through history was taken from the three cases and complete drug history excluding any other recent drug intake or use of dyes or stains. Virology was negative in the three cases with no associated liver diseases or endocrine abnormalities. The first case regained her normal hair color 1 month after stopping Heptaminol as well as the third patient who regained his color only few days after stopping the drug. The second patient had just stopped the drug few days ago and we are following her.

\section{Discussion}

This is the second case report of hair lightening in a Hemodialysis patienttaking Heptaminol, we did not find any other case reports. Alterations in the cutaneous pigmentation is mainly hyperpigmentation on sun-exposed areas due to an increase in melanin in the basal layer and superficial dermis due to failure of the kidneys to excrete beta-melanocyte-stimulating hormone (b-MSH), and yellowish tinge to the skin due to accumulation of carotenoids and urochromes in the dermis, epidermis or subcutaneous tissue [1,6]. Hypopigmentation of skin and hair was reported in only 6 dialysis patients in a prospective study including 363 patients and the pathogenesis of these changes was poorly understood [3]. Another case study reported one hemodialysis patient who developed acquired hair and skin fairness and the cause was attributed to a disturbance in phenylalanine metabolism [10]. Many drugs were identified to cause lightening of hair such as Chloroquine, Interferon alpha, Phenols, Benzoyl peroxide, Etretinate, Phenylthiourea and Triparanol [11] (Figures 1-5). 


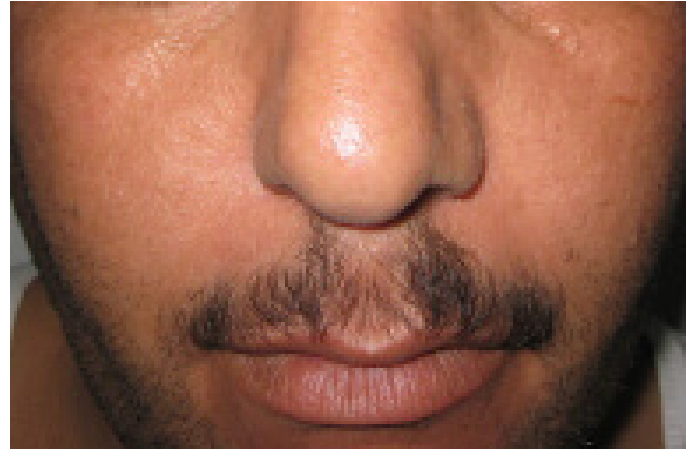

Figure 1:

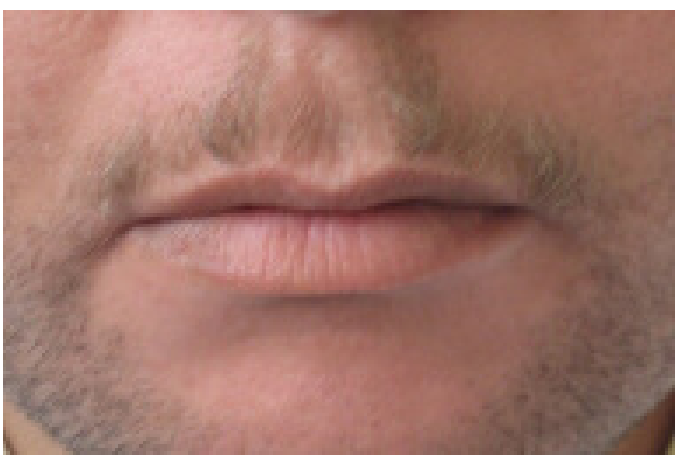

Figure 2:

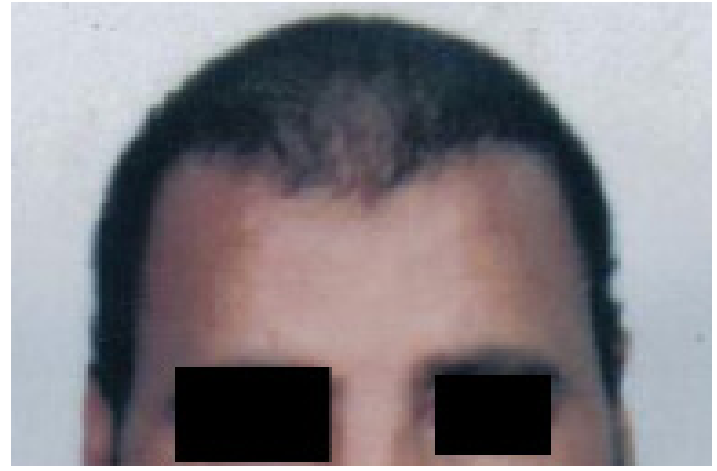

Figure 3:

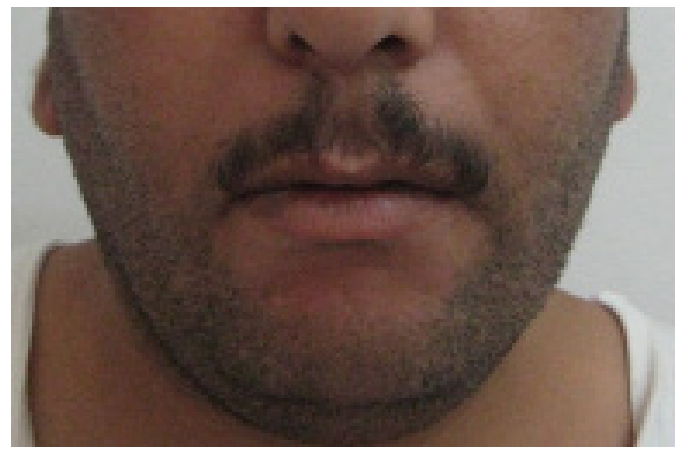

Figure 4:

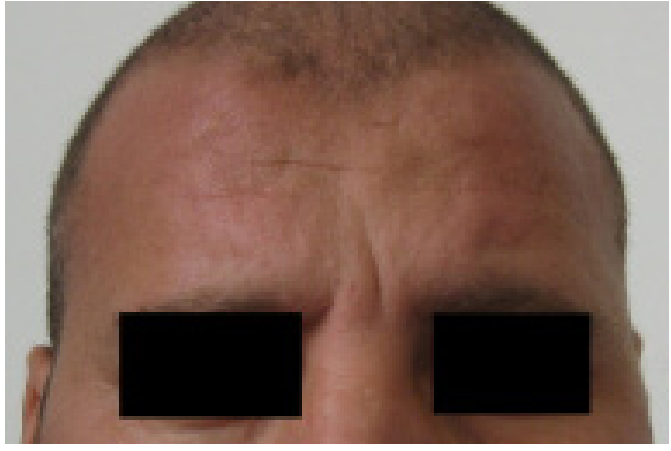

Figure 5:

\section{Conclusion}

To our knowledge, no cases with such changes were reported with non-hemodialysis patients receiving Heptaminol, which suggests a combined effect of Heptaminol and changes in hair structure, melanin production altered by end stage renal disease, or certain trace elements deficiency with possible genetic or environmental predisposition.

\section{References}

1. Sanai M, Aman S, Nadeem M, Kazmi AH (2010) Dermatologic manifestations in patients of renal disease on hemodialysis. Journal of Pakistan Association of Dermatologists 20(3): 163-168.

2. Avermaete A, Altmeyer P, Buhles MB (2001) Skin changes in dialysis patients: a review. Nephrology Dialysis Transplantation 16(12): 22932296.

3. Masmoudi A, Ben Hmida M, Mseddi M, Meziou TJ, Walha N, et al. (2006) Cutaneous manifestations of chronic hemodialysis. Prospective study of 363 cases. Presse Med 35(3 Pt 1): 399-406.

4. Picó MR, Somolinos LA, Sánchez JL, Calderón BR (1992) Cutaneous alterations in patients with chronic renal failure. Int J Dermatol 31(12): 860-863.

5. Hajheydari Z, Makhlough A (2008) Cutaneous and mucosal manifestations in patients on maintenance hemodialysis: a study of 101 patients in Sari, Iran. Iran J Kidney Dis 2(2): 86-90.

6. Udayakumar P, Balasubramanian S, Ramalingam KS, Lakshmi C, Srinivas CR, et al. (2006) Cutaneous manifestations in patients with chronic renal failure on hemodialysis. Indian J Dermatol Venereol Leprol 72(2): 119-125.

7. Mirza R, Wahid Z, Talat H (2012) Dermatological manifestations in chronic renal failure patients on Haemodialysis. JLUMHS 11(1).

8. Piraccini BM, Iorizzo M, Rech G, Tosti A (2006) Drug-induced hair disorders. Curr Drug Saf 1(3): 301-305.

9. Leila G, Kawtar Z, Benyouness, Hakima B (2009) Hair lightening in an hemodialysis patient treated by heptaminol (heptamyl). Dermatology Online Journal 15(4): 16

10. Hmida MB, Turki H, Hachicha J, Reygagne P, Rabier D, et al. (1996) Hypopigmentation in hemodialysis. Acquired hair and skin fairness in a uremic patient undergoing maintenance hemodialysis: case report and review of the literature. Dermatology 192(2): 148-152.

11. Tosti A, Piraccin BM (2005) Diagnosis and Treatment of Hair Disorders: An Evidence-Based Atlas. p. 78.

For possible submissions Click below: 